\title{
Diabetes Insipidus: A Challenging Diagnosis with New Drug Therapies
}

\author{
Chadi Saifan, Rabih Nasr, Suchita Mehta, Pranab Sharma Acharya, Isera Perrera, \\ Giovanni Faddoul, Nikhil Nalluri, Mayurakhan Kesavan, Yorg Azzi, and Suzanne El-Sayegh
}

Division of Nephrology, Department of Medicine, Staten Island University Hospital, 475 Seaview Avenue, Staten Island, NY 10305, USA

Correspondence should be addressed to Rabih Nasr; nasr_rabih@yahoo.com

Received 31 January 2013; Accepted 21 February 2013

Academic Editors: M. Léone and D. Malhotra

Copyright (C) 2013 Chadi Saifan et al. This is an open access article distributed under the Creative Commons Attribution License, which permits unrestricted use, distribution, and reproduction in any medium, provided the original work is properly cited.

Diabetes Insipidus (DI) is either due to deficient secretion of arginine vasopressin (central) or to tubular unresponsiveness (nephrogenic). Drug induced DI is a well-known entity with an extensive list of medications. Polyuria is generally defined as urine output exceeding 3 liters per day in adults. It is crucial to identify the cause of diabetes insipidus and to implement therapy as early as possible to prevent the electrolyte disturbances and the associated mortality and morbidity. It is very rare to have an idiosyncratic effect after a short use of a medication, and physicians should be aware of such a complication to avoid volume depletion. The diagnosis of diabetes insipidus is very challenging because it relies on laboratory values, urine output, and the physical examination of the patient. A high clinical suspicion of diabetes insipidus should be enough to initiate treatment. The complications related to DI are mostly related to the electrolyte imbalance that can affect the normal physiology of different organ systems.

\section{Background}

Though it is a rare disorder, diabetes insipidus was first described in the 18th century [1]. Diabetes insipidus (DI) is either due to deficient secretion of arginine vasopressin (AVP), also known as antidiuretic hormone (ADH) by the pituitary gland (central diabetes insipidus) or due to renal tubular unresponsiveness to AVP (nephrogenic DI). This leads to polyuria, polydipsia with hyposthenuria, causing dehydration and hypernatremia if the patient is deprived of water [2].

\section{Etiology}

Deficiency of AVP secretion is referred to as central DI, pituitary DI, or neurohypophyseal DI. About $50 \%$ of central DI cases are idiopathic [3]. It usually appears within 24 hours followed by a 2-3-week period of inappropriate antidiuresis. In a German study, only $8.7 \%$ of DI cases persisted for more than 3 months [4].

Close followup of patients diagnosed with idiopathic DI is necessary to detect slowly growing intracranial lesions.
Lung and breast cancer are most common malignancies [5]. Leukemias and lymphomas are known to associate with DI [6].

The incidence of acute DI in severe head injury is high $[7,8] .16 \%$ of central DI is secondary to head trauma.

There are several autosomal recessive forms and $\mathrm{X}$ linked recessive forms were described causing DI. Gestational DI which manifests during pregnancy and usually remits several weeks after delivery is caused by deficiency of plasma AVP. [9].

Other causes of central DI include infiltrative disorders (histiocytosis X, sarcoidosis) anorexia nervosa, infections such as viral meningitis toxoplasmosis, inflammatory conditions including lupus erythematosis, wegener's, and vascular lesions, such as arteriovenous malformations or aneurysms (Table 1).

Majority of cases of hereditary nephrogenic DI have $\mathrm{X}$-linked inheritance [10]. Hypercalcemia causes defective urinary concentrating ability which is generally reversible with correction of the hypercalcemia and may be associated with reductions both in sodium chloride reabsorption on 


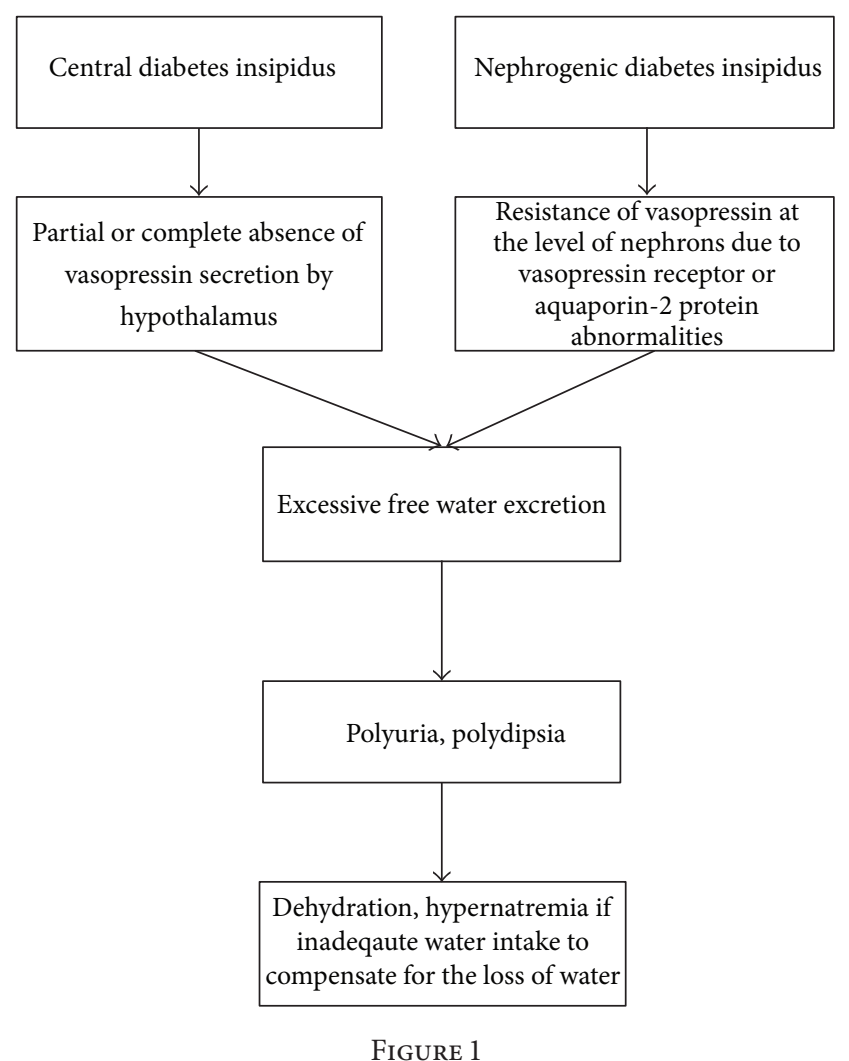

the thick ascending limb of the loop of Henle, thereby interfering with the countercurrent mechanism. Persistent severe hypokalemia can have similar effects in the collecting tubule and the thick ascending limb of the loop of Henle. A variety of renal diseases can give rise to nephrogenic DI. Apart from lithium multiple medications are associated with nephrogenic DI (Table 2).

\section{Epidemiology}

Neurosurgical procedures, tumors, traumatic brain injury, tumors, infiltrative lesions, and malformations are the most frequent causes of DI.

Normal Physiology of Vasopressin. Arginine vasopressin is an antidiuretic hormone that is first synthesized in cell bodies of the nuclei in the hypothalamus and then transported to the posterior pituitary gland [11]. Although there are many factors responsible for the secretion of vasopressin like nausea, acute hypoglycemia, glucocorticoid deficiency, smoking, the most important stimulus is increased plasma osmolality [12]. The increase in plasma osmolality can be as small as $1 \%$. [13]. The baroregulatory system usually does not cause the secretion of vasopressin during the normal circumstances unless there is a large volume loss, in which case there is release of some amount of this hormone [14]. Vasopressin acts as an antidiuretic by reabsorbing water via the principle cells of collecting ducts and the thick ascending loop of Henle, thereby increasing the plasma blood volume and decreasing the plasma osmolality $[15,16]$. It can also cause
TABLE 1: Causes of central diabetes insipidus.

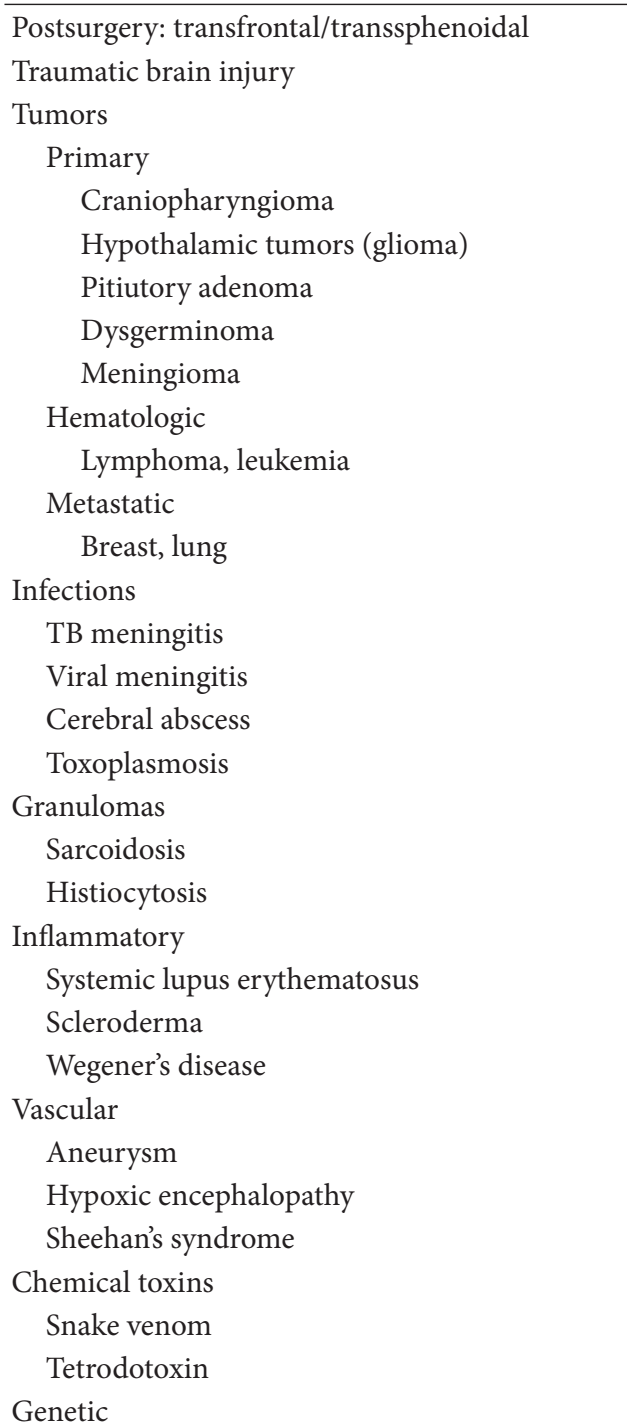

contraction of the smooth muscles in the blood vessels [13] and release of von Willebrand factor [17].

Vasopressin Receptors. There are different types of receptor for vasopressin. The V1 receptor present in the endothelial cells leads to a pressor effect by the activation of $\mathrm{Ca}++$ pathway whereas the V2R is the one responsible for water reabsorption by activating cyclic adenosine monophosphate (cAMP) in the kidneys and opening of the aquaporin channels $[18,19]$.

\section{Pathophysiology: Figure 1}

Irrespective of the cause of diabetes insipidus, whether central or nephrogenic, hereditary or acquired, the consequences are similar as shown in the chart above with loss of free water. This leads to dehydration if the patient is not able to keep up with urinary loss and may cause hypernatremia.

4.1. Central Diabetes Insipidus. The central causes of diabetes insipidus are either due to decreased secretion of vasopressin 
TABLE 2: Causes of nephrogenic diabetes insipidus.

\begin{tabular}{l}
\hline Drugs \\
Lithium \\
Ofloxacin \\
Demeclocycline \\
Amphotericin B \\
Aminoglycosides \\
Cisplatin \\
Cidofovir \\
Foscarnet \\
Ifosfamide \\
Didanosine \\
Ifosfamide \\
Postobstructive \\
Vascular \\
Sickle cell disease and trait \\
Acute tubular necrosis \\
Metabolic \\
Severe hypercalcemia \\
Severe hypokalemia \\
Infiltration \\
Amyloidosis \\
Sjögren's syndrome \\
Granulomas \\
Garcoma \\
Genetic \\
\end{tabular}

or secretion of partially functional form of vasopressin. The causes of central diabetes insipidus are hereditary, congenital or acquired. The hereditary form includes an autosomal dominant disorder with mutation of the AVP-neurophysin II gene [20]. One of the forms of the disease, the X-linked recessive and autosomal recessive forms due to mutations of the WFS 1 gene responsible for Wolfram's syndrome can also cause diabetes insipidus [21]. Deficiency of vasopressin can occur during pregnancy from increased breakdown by an N-terminal aminopeptidase that is usually produced in the placenta [22]. There are many acquired causes of diabetes insipidus as described above.

4.2. Nephrogenic Diabetes Insipidus. The nephrogenic causes of diabetes insipidus are due to abnormalities of the vasopressin receptor V2R and aquaporin-2 protein water channels $[23,24]$. The mechanism of lithium in causation of diabetes insipidus is still debated and there are many hypotheses [25]. Lithium causes decreased AQP2 and AQP3 expression and thus free water loss in the collecting duct [26]. Electrolyte abnormalities like hypokalemia and hypercalcemia can cause resistance to vasopressin $[27,28]$. Chronic bilateral ureteral obstruction can cause decreased aquaporin protein expression $[29,30]$.

\section{Clinical Manifestations}

The age of presentation is dependent on the etiology, it can present at any age, and the prevalence is equal among males and females although there is one study showing higher prevalence in the males [31]. In an alert and conscious patient, diabetes insipidus presents with intense thirst (polydipsia), craving for ice water together with polyuria. The volume of fluid ingested may range from $2 \mathrm{~L}$ to even $20 \mathrm{~L}$ a day [32]. Less-severe cases may present with persistent enuresis. Most patients with an intact hypothalamic thirst centre maintain their fluid balance by drinking water. But patient who are unable to access free water as seen in neonates and elderly present with clinical features of hypernatremia and dehydration [33]. Lethargy, altered mental status, hyperreflexia, seizure, or, may be other presenting symptoms especially in the older age group, neonates and infants. Dehydration may lead to contraction of intravascular volume which in severe cases causes traction of dural veins and sinuses leading to intracranial hemorrhage.

During pregnancy, diabetes insipidus is associated with oligohydramnios, preeclampsia, and even hepatic dysfunction [34].

\section{Diagnosis of Diabetes Insipidus}

Polyuria is generally defined as urine output exceeding 3 liters per day in adults. Usually polyuria could be caused by other conditions such as primary polydipsia, osmotic diuresis, and prostatic hypertrophy. It is crucial to identify the cause of diabetes insipidus and to implement therapy as early as possible to prevent the electrolyte disturbances and the associated morbidity and mortality.

In order to distinguish diabetes insipidus from other forms of polyuria, several blood tests have to be ordered including the blood glucose, plasma osmolality, bicarbonate levels, electrolytes, and urinalysis along with urine osmolality.

High blood glucose levels along with an osmolar excretion rate, which is equal to urine output multiplied by urine osmolality, above $1000 \mathrm{mosm} / \mathrm{d}$ indicates osmotic diuresis secondary to hyperglycemia. Other causes of osmotic diuresis could be due to urea as in post-AKI and mannitol and giving high intravenous sodium loads causing iatrogenic osmotic diuresis.

When the osmolar excretion rate is less than $1000 \mathrm{mOsm} /$ $\mathrm{d}$, two conditions have to be examined including primary polydipsia which is associated with a serum sodium of $<140 \mathrm{meq} / \mathrm{L}$ and a dilute urine with urine osmolality of $<100 \mathrm{mOsm} / \mathrm{Kg}$ on the one hand and diabetes insipidus on the other hand. It is associated with a serum sodium above $140 \mathrm{meq} / \mathrm{L}$ and a urine osmolality above $100 \mathrm{mOsm} / \mathrm{Kg}$.

The water deprivation test helps to distinguish between the different causes of polyuria. It should be done by experienced physicians. It entails withholding any fluid intake from the patient. The normal physiologic response to water deprivation test leads to increase in antidiuretic hormone as the plasma osmolality increases and subsequently an increase in urine osmolality [35-37]. The effect of antidiuretic hormone would be maximal when the plasma osmolality 
TABLE 3

Water restriction test
Urine osmolality

reaches $295-300 \mathrm{mOsmol} / \mathrm{Kg}$ or when the serum sodium is above $145 \mathrm{meq} / \mathrm{L}$. At this point, administering desmopressin will not further increase the urine osmolality only if we have deficient endogenous arginine vasopressin as in central diabetes insipidus.

The water restriction test helps to determine the cause of polyuria. First, it could be due to excessive drinking as in primary polydipsia. Second, it could be due to insufficient endogenous antidiuretic hormone, hence it is called central diabetes insipidus. And third, it could be due to resistance of the kidney to antidiuretic hormone, called nephrogenic diabetes insipidus.

Patients should stop drinking. After 2 to 3 hours of cessation of fluid intake, the urine volume and osmolality should be measured every hour and the plasma sodium and plasma osmolality every 2 hours. The test is continued till we reach one of the following endpoints.

(1) The urine osmolality increases to reach a value above $600 \mathrm{mOsmol} / \mathrm{Kg}$, it means that this is an appropriate response, and endogenous antidiuretic hormone is intact. The urine osmolality remains steady on 2 subsequent measurements and the plasma osmolality is rising. The plasma sodium level rises to reach a level above $145 \mathrm{meq} / \mathrm{L}$ or a plasma osmolality become between 295 and $300 \mathrm{mOsmol} / \mathrm{Kg}$.

Desmopressin is then given in the last two conditions either subcutaneously or intravenously as $4 \mathrm{mcg}$ or intranasally as $10 \mathrm{mcg}$. The urine volume and osmolality and plasma osmolality are followed closely and the variations should be recorded.

Different patterns to water restriction and desmopressin administration will help to discriminate between the different causes of polyuria [35, 38-40]. Refer to Table 3.

(2) The urine osmolality increases in complete central diabetes insipidus with water deprivation test, usually to more than $300 \mathrm{mOsmol} / \mathrm{Kg}$. Desmopressin leads to an increase in urine osmolality to more than $100 \%$ in complete central diabetes insipidus and $15-50 \%$ in partial central diabetes insipidus.

In nephrogenic diabetes insipidus, water deprivation test leads to a rise in urine osmolality but usually less than $300 \mathrm{mOsmol} / \mathrm{Kg}$ and desmopressin produces little or no change in urine osmolality.

In primary polydipsia, water deprivation test produces a rise in urine osmolality but desmopressin administration produces no change since the endogenous arginine vasopressin function and secretion are intact.

\section{Differential Diagnosis}

Diabetes insipidus must be differentiated from other causes of polyuria (Box 1).

\section{Treatment}

Mild cases of DI may not even need treatment and sufficient water intake may suffice. The removal of aggravating factors (e.g.,: reductions in glucocorticoids that directly cause free water clearance) improves polyuria.

Central DI. Earlier preparations available for treatment of central DI included acetone-dried extract from posterior pituitary of cows and pigs. Variable duration of action and local irritation limited its use, and hence a more purified form of $\mathrm{ADH}$ preparation was made that could be administered intramuscularly. But side effects of abdominal cramps, angina and hypertension lead to the development of other drugs.

Desmopressin. DDAVP (1-deamino-8-arginine vasopressin): this has established itself as a drug of choice for the longterm management of central DI [41]. It is a synthetic, longacting vasopressin analog with minimal pressor activity but 


\author{
Causes of polyuria: \\ (i) psychogenic polydipsia \\ (ii) diabetes mellitus \\ (iii) cushing syndrome \\ (iv) drugs: corticosteroid, lithium, demeclocycline, lithium, \\ foscarnet, methicillin \\ (v) hypercalcemia \\ (vi) hypokalemia \\ (vii) nocturnal polyuria of Parkinson disease
}

Box 1

has nearly two-fold antidiuretic potency of arginine vasopressin. Pregnancy, and puerperium-associated DI will also benefit from desmopressin as it is resistant to degradation by circulating vasopressinase. Dosing is started at night to give relief for nocturnal polyuria, and day-time dosages are added as per need to control day-time symptoms. It can be given nasally, parenterally, or orally. Oral preparation is preferred for patients with sinusitis. Recently introduced lyophilisate melts under the tongue, may be preferred in children, and has a better bioavailability.

Starting dose of oral desmopressin is typically $0.05 \mathrm{mg}$ twice daily and increased to a maximum of $0.4 \mathrm{mg}$ every 8 hours if needed. Nasal preparation $(100 \mathrm{mcg} / \mathrm{mL}$ solution) may be started at a dose of $0.05-0.1 \mathrm{~mL}$ every $12-24$ hours through a metered dose nasal inhaler. Further dosing is individualized according to the degree of polyuria and is mainly aimed at eliminating night symptoms. Patient should be monitored for water intoxication and hyponatremia. It has been linked to depression with an increased risk of suicide, agitation and erythromelalgia.

Carbamazepine. This anticonvulsant drug increases the renal sensitivity to the ADH effect [42]. In vivo studies showed carbamazepine decreased the urinary volume and increased the urinary osmolality by increasing that aquaporin 2 expression in the inner medullary collecting duct [43].

Chlorpropamide. This has been frequently used in mild CDI. It potentiates the antidiuretic action of circulating arginine vasopressin and leads to a reduction of urinary output by nearly fifty percent. It has an extensive side effect profile including hypo/hyperglycemia, hyponatremia, hyperlipidemia, hyperuricemia, hypercalcemia, hypokalemia, metabolic alkalosis, and myopathy. Hence certain studies proposed indapamide as a lowcost alternative for chlorpropamide.

Indapamide. This antihypertensive diuretic drug appears as an alternative drug for mild form of CDI as it increases urinary osmolality and decrease serum osmolality [44].

Nephrogenic DI. The acute management of NDI involves correcting sodium levels by replacing free water deficits. Chronic NDI management involves reversing the cause if possible.

Lithum-induced NDI can be managed to a large extent by simply increasing water intake, given that the thirst mechanism is intact. If required, amiloride at doses $2.5-10 \mathrm{mg} / \mathrm{dL}$ can be used. Amiloride decreases the lithium entry into principal cells by inhibiting ENaC. Thiazides induce hypovolemia and increase the proximal tubular water reabsorption and thus reduce polyuria. NSAIDS on the other hand can reduce the negative effect of intrarenal prostaglandins on urinary concentrating mechanism and help manage NDI.

\section{Prognosis}

Central DI occurring after pituitary surgery usually remits within days to weeks but if structural damage has occurred to the stalk, it may even be permanent. The clinical course of chronic central DI is more of inconvenience to daily life than a dire medical condition. Currently available treatments do a good job to control symptoms but patients must be watched closely for side effects, water intoxication, and hypernatremia.

\section{References}

[1] J. Lindholm, "Diabetes insipidus: historical aspects," Pituitary, vol. 7, no. 1, pp. 33-38, 2004.

[2] J. G. Verbalis, "Diabetes insipidus," Reviews in Endocrine and Metabolic Disorders, vol. 4, no. 2, pp. 177-185, 2003.

[3] M. Maghnie, G. Cosi, E. Genovese et al., "Central diabetes insipidus in children and young adults," The New England Journal of Medicine, vol. 343, no. 14, pp. 998-1007, 2000.

[4] R. A. Kristof, M. Rother, G. Neuloh, and D. Klingmüller, "Incidence, clinical manifestations, and course of water and electrolyte metabolism disturbances following transsphenoidal pituitary adenoma surgery: a prospective observational study: clinical article," Journal of Neurosurgery, vol. 111, no. 3, pp. 555562, 2009.

[5] H. Y. Yap, C. K. Tashima, G. R. Blumenschein, and N. Eckles, "Diabetes insipidus and breast cancer," Archives of Internal Medicine, vol. 139, no. 9, pp. 1009-1011, 1979.

[6] A. I. Rosenzweig and J. W. Kendall, "Diabetes insipidus as a complication of acute leukemia," Archives of Internal Medicine, vol. 117, no. 3, pp. 397-400, 1966.

[7] P. Hadjizacharia, E. O. Beale, K. Inaba, L. S. Chan, and D. Demetriades, "Acute diabetes insipidus in severe head injury: a prospective study," Journal of the American College of Surgeons, vol. 207, no. 4, pp. 477-484, 2008.

[8] J. C. Boughey, M. J. Yost, and R. P. Bynoe, "Diabetes insipidus in the head-injured patient," The American Surgeon, vol. 70, no. 6, pp. 500-503, 2004. 
[9] J. A. Durr, "Diabetes insipidus in pregnancy," American Journal of Kidney Diseases, vol. 9, no. 4, pp. 276-283, 1987.

[10] M. F. Arthus, M. Lonergan, M. J. Crumley et al., "Report of 33 novel AVPR2 mutations and analysis of 117 families with Xlinked nephrogenic diabetes insipidus," Journal of the American Society of Nephrology, vol. 11, no. 6, pp. 1044-1054, 2000.

[11] K. E. Barrett, Ganong's Review of Medical Physiology, McGrawHill, New York, NY, USA, 23rd edition, 2009.

[12] H. M. Kronenberg, S. Melmed, K. S. Polonsky, and P. Reed Larsen, Williams Textbook of Endocrinology, Saunders, 11th edition, 2008.

[13] D. L. Kasper, Ed., Harrison's Principles of Internal Medicine, McGraw-Hill, New York, NY, USA, 17th edition, 2008.

[14] A. W. Cowley Jr., E. Monos, and A. C. Guyton, "Interaction of vasopressin and the baroreceptor reflex system in the regulation of arterial blood pressure in the dog," Circulation Research, vol. 34, no. 4, pp. 505-514, 1974.

[15] J. J. Grantham and M. B. Burg, "Effect of vasopressin and cyclic AMP on permeability of isolated collecting tubules," The American Journal of Physiology, vol. 211, no. 1, pp. 255-259, 1966.

[16] G. Fejes-Toth and A. Naray-Fejes-Toth, "Isolated principal and intercalated cells: hormone responsiveness and $\mathrm{Na}^{+}-\mathrm{K}^{+}$-ATPase activity," American Journal of Physiology, vol. 256, no. 4, pp. F742-F750, 1989.

[17] J. E. Kaufmann, A. Oksche, C. B. Wollheim, G. Günther, W. Rosenthal, and U. M. Vischer, "Vasopressin-induced von Willebrand factor secretion from endothelial cells involves V2 receptors and cAMP," Journal of Clinical Investigation, vol. 106, no. 1, pp. 107-116, 2000.

[18] A. Morel, A. M. O'Carroll, M. J. Brownstein, and S. J. Lolait, "Molecular cloning and expression of a rat Vla arginine vasopressin receptor," Nature, vol. 356, no. 6369, pp. 523-526, 1992.

[19] T. Sugimoto, M. Saito, S. Mochizuki, Y. Watanabe, S. Hashimoto, and H. Kawashima, "Molecular cloning and functional expression of a cDNA encoding the human $\mathrm{V}(\mathrm{lb})$ vasopressin receptor," Journal of Biological Chemistry, vol. 269, no. 43, pp. 2708827092, 1994.

[20] J. H. Christensen, C. Siggaard, and S. Rittig, "Autosomal dominant familial neurohypophyseal diabetes insipidus," APMIS. Supplementum, vol. 111, no. 109, pp. 92-95, 2003.

[21] S. S. Najjar, M. G. Saikaly, G. M. Zaytoun, and A. Abdelnoor, "Association of diabetes insipidus, diabetes mellitus, optic atrophy, and deafness. The Wolfram or DIDMOAD syndrome," Archives of Disease in Childhood, vol. 60, no. 9, pp. 823-828, 1985.

[22] N. Aleksandrov, F. Audibert, M. J. Bedard, M. Mahone, F. Goffinet, and I. J. Kadoch, "Gestational diabetes insipidus: a review of an underdiagnosed condition," Journal of Obstetrics and Gynaecology Canada, vol. 32, no. 3, pp. 225-231, 2010.

[23] D. G. Bichet, "Vasopressin receptor mutations in nephrogenic diabetes insipidus," Seminars in Nephrology, vol. 28, no. 3, pp. 245-251, 2008.

[24] P. I. Nedvetsky, G. Tamma, S. Beulshausen, G. Valenti, W. Rosenthal, and E. Klussmann, "Regulation of aquaporin-2 trafficking," Handbook of Experimental Pharmacology, no. 190, pp. 133-157, 2009.

[25] Brenner \& Rector's the Kidney, 9th edition, 2011.

[26] D. Marples, S. Christensen, E. I. Christensen, P. D. Ottosen, and S. Nielsen, "Lithium-induced downregulation of aquaporin-2 water channel expression in rat kidney medulla," Journal of Clinical Investigation, vol. 95, no. 4, pp. 1838-1845, 1995.
[27] D. Marples, J. Frøkiær, J. Dørup, M. A. Knepper, and S. Nielsen, "Hypokalemia-induced downregulation of aquaporin-2 water channel expression in rat kidney medulla and cortex," Journal of Clinical Investigation, vol. 97, no. 8, pp. 1960-1968, 1996.

[28] J. M. Sands, F. X. Flores, A. Kato et al., "Vasopressin-elicited water and urea permeabilities are altered in IMCD in hypercalcemic rats," American Journal of Physiology, vol. 274, no. 5, pp. F978-F985, 1998.

[29] J. Frokiaer, D. Marples, M. A. Knepper, and S. Nielsen, "Bilateral ureteral obstruction downregulates expression of vasopressinsensitive AQP-2 water channel in rat kidney," American Journal of Physiology, vol. 270, no. 4, pp. F657-F668, 1996.

[30] C. Li, W. Wang, T. H. Kwon et al., "Downregulation of AQP1, -2, and -3 after ureteral obstruction is associated with a long-term urine-concentrating defect," American Journal of Physiology, vol. 281, no. 1, pp. F163-F171, 2001.

[31] A. M. Moses, "Clinical and laboratory observations in the adult with diabetes insipidus and related syndromeseds," in Diabetes Insipidus in Man. Frontiers of Hormone Research, P. Czernichow and A. G. Robinson, Eds., vol. 13, p. 156, S Karger, Basel, Switzerland, 1985.

[32] G. L. Robertson, "Diagnosis of diabetes insipidus," in Diabetes Insipidus in Man. Frontiers of Hormone Research, P. Czernichow and A. G. Robinson, Eds., vol. 13, p. 176, S Karger, Basel, Switzerland, 1985.

[33] P. H. Baylis, "Diabetes insipidus," Medicine, vol. 25, pp. 9-11, 1997.

[34] S. Ananthakrishnan, "Diabetes insipidus in pregnancy: etiology, eva luation, and management," Endocrine Practice, vol. 15, no. 4, pp. 377-382, 2009.

[35] B. D. Rose and T. W. Post, Clinical Physiology of Acid-Base and Electrolyte Disordersed, McGraw-Hill, New York, NY, USA, 5th edition, 2001.

[36] M. Miller, T. Dalakos, A. M. Moses, H. Fellerman, and D. H. Streeten, "Recognition of partial defects in antidiuretic hormone secretion," Annals of Internal Medicine, vol. 73, no. 5, pp. 721-729, 1970.

[37] R. L. Zerbe and G. L. Robertson, "A comparison of plasma vasopressin measurements with a standard indirect test in the differential diagnosis of polyuria," The New England Journal of Medicine, vol. 305, no. 26, pp. 1539-1546, 1981.

[38] G. L. Robertson, "Diseases of the posterior pituitary," in Endocrinology and Metabolism, D. Felig, J. D. Baxter, A. E. Broadus, and L. A. Frohman, Eds., pp. 251-277, McGraw-Hill, New York, NY, USA, 1981.

[39] M. Miller, T. Dalakos, A. M. Moses, H. Fellerman, and D. H. Streeten, "Recognition of partial defects in antidiuretic hormone secretion," Annals of Internal Medicine, vol. 73, no. 5, pp. 721-729, 1970.

[40] R. L. Zerbe and G. L. Robertson, "A comparison of plasma vasopressin measurements with a standard indirect test in the differential diagnosis of polyuria," The New England Journal of Medicine, vol. 305, no. 26, pp. 1539-1546, 1981.

[41] K. S. L. Lam, M. S. Wat, K. L. Choi, T. P. Ip, R. W. C. Pang, and C. R. Kumana, "Pharmacokinetics, pharmacodynamics, long-term efficacy and safety of oral 1-deamino-8-D-arginine vasopressin in adult patients with central diabetes insipidus," British Journal of Clinical Pharmacology, vol. 42, no. 3, pp. 379385, 1996.

[42] R. M. Lane, "SSRIs and hyponatraemia," The British Journal of Clinical Practice, vol. 51, no. 3, pp. 144-146, 1997. 
[43] A. C. De Bragana, Z. P. Moyses, and A. J. Magaldi, "Carbamazepine can induce kidney water absorption by increasing aquaporin 2 expression," Nephrology Dialysis Transplantation, vol. 25, no. 12, pp. 3840-3845, 2010.

[44] J. D. Cook, Y. H. Caplan, C. P. LoDico, and D. M. Bush, "The characterization of human urine for specimen validity determination in workplace drug testing: a review," Journal of Analytical Toxicology, vol. 24, no. 7, pp. 579-588, 2000. 


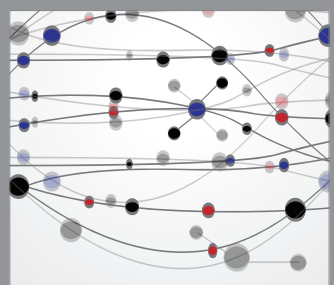

The Scientific World Journal
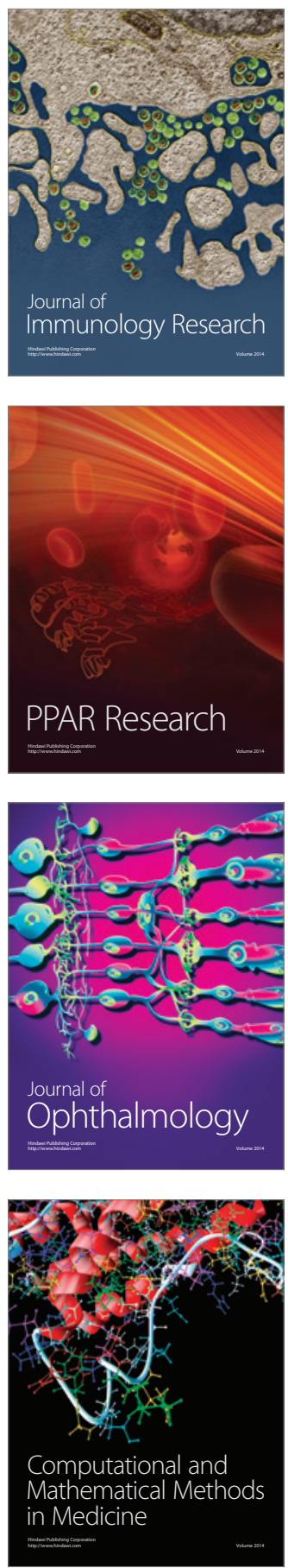

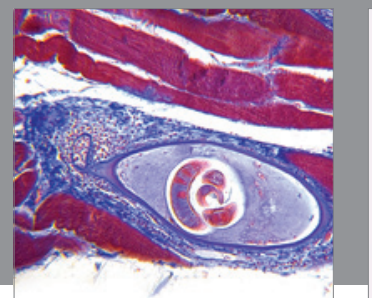

Gastroenterology

Research and Practice
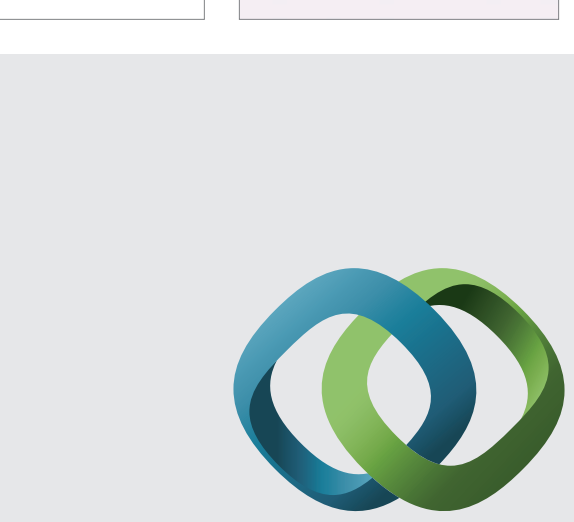

\section{Hindawi}

Submit your manuscripts at

http://www.hindawi.com
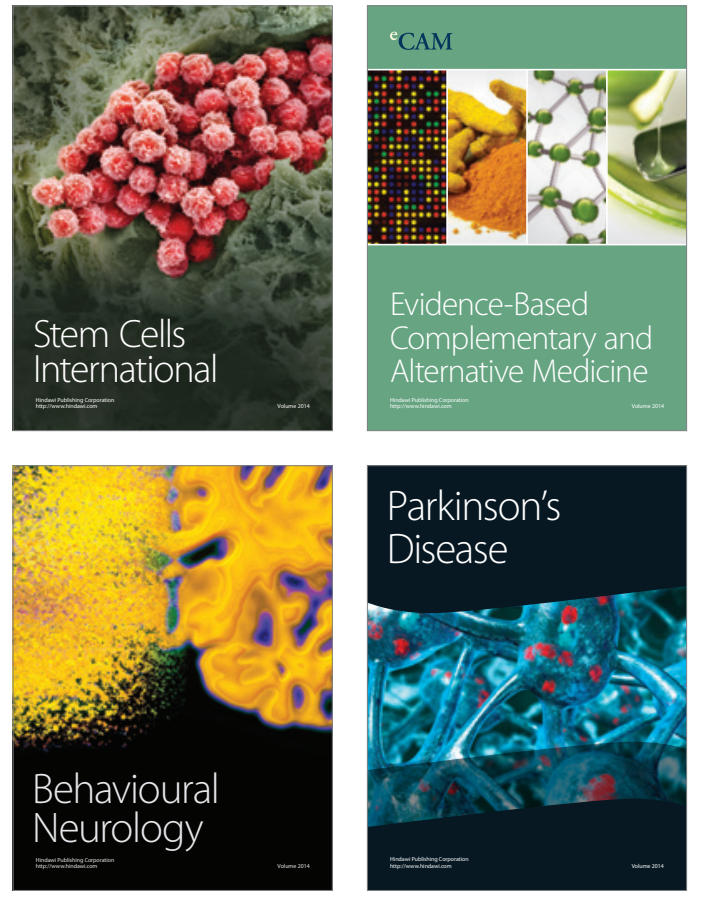
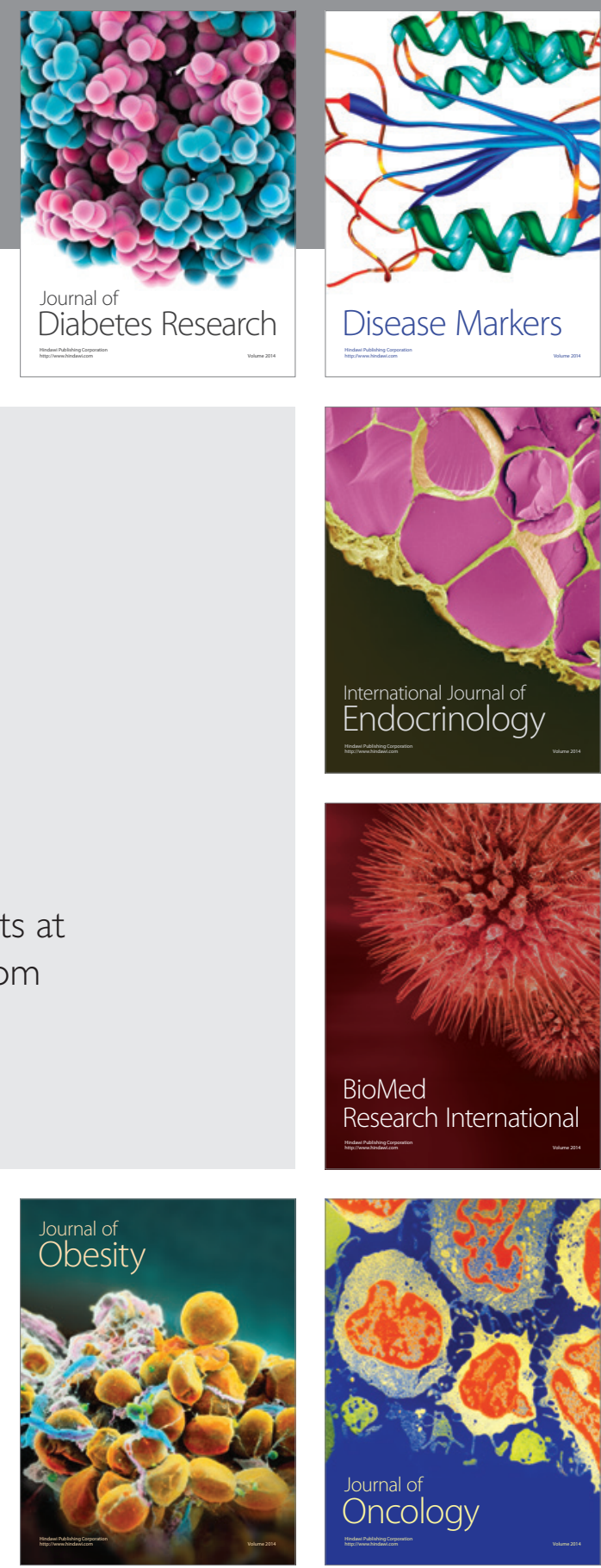

Disease Markers
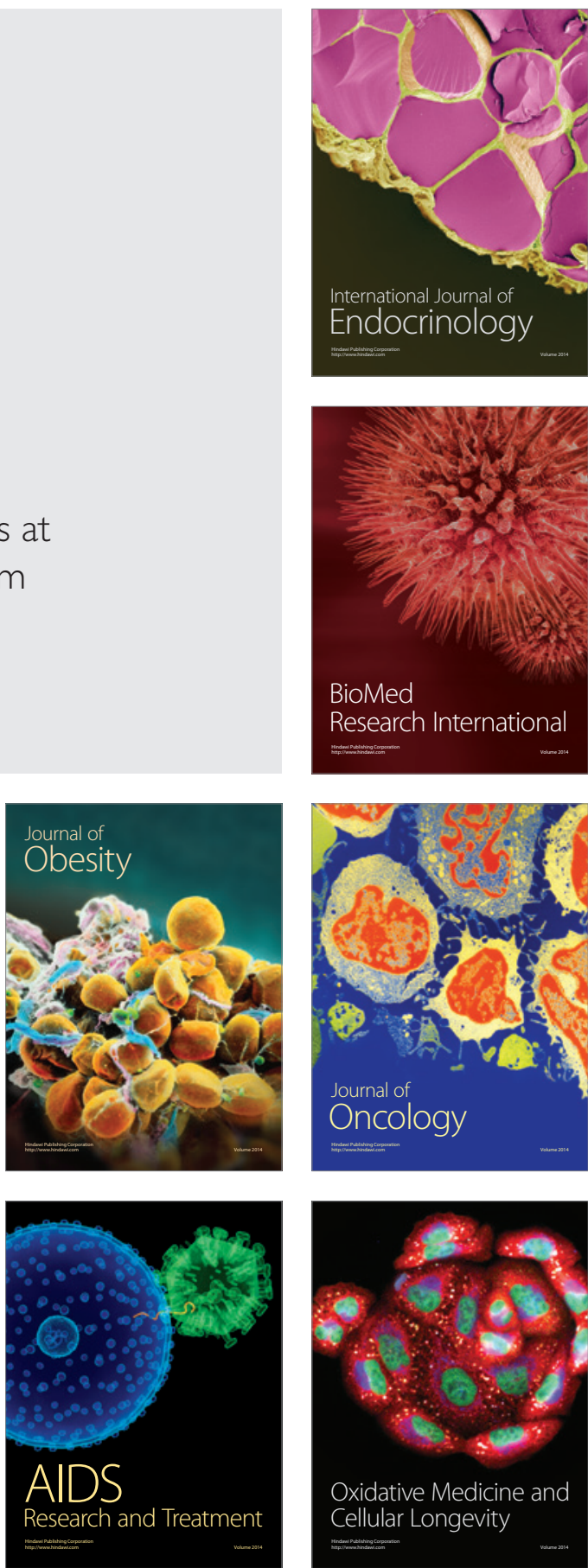